\title{
Distribuição de tipos de Papillomavirus humano em mulheres de grupos minoritários étnicos: revelando lacunas na América do Sul
}

Distribution of human Papillomavirus types in women from ethnic minority groups: revealing gaps in South America

Distribución de los tipos de Papillomavirus humano en mujeres de grupos étnicos minoritarios: brechas reveladoras en América del Sur

Recebido: 21/07/2021 | Revisado: 26/07/2021 | Aceito: 02/08/2021 | Publicado: 07/08/2021

José de Ribamar Ross

ORCID: https://orcid.org/0000-0002-9362-8651 Universidade Estadual do Maranhão, Brasil E-mail: joseross@professor.uema.br

Marco Aurélio Palazzi Safádi

ORCID: https://orcid.org/0000-0002-4401-9446 Faculdade de Ciências Médicas da Santa Casa de São Paulo, Brasil E-mail: masafadi@uol.com.br

Maria do Desterro Soares Brandão Nascimento ORCID: https://orcid.org/0000-0003-2783-362X Universidade Federal do Maranhão, Brasil E-mail: cnsd.ma@gmail.com

Zulmira da Silva Batista ORCID: https://orcid.org/0000-0003-1503-7802 Universidade Federal do Maranhão, Brasil E-mail: zubatista@yahoo.com.br

Flavia Castello Branco Vidal

ORCID: https://orcid.org/0000-0002-2075-5780 Universidade Federal do Maranhão, Brasil E-mail: flavidal@hotmail.com

Gerusinete Rodrigues Bastos dos Santos

ORCID: https://orcid.org/0000-0002-1602-4563 Universidade Federal do Maranhão, Brasil E-mail: gerusinete@hotmail.com

Nytale Lindsay Cardoso Portela ORCID: https://orcid.org/0000-0002-5067-0884

Universidade Federal do Maranhão, Brasil E-mail: nytalelindsay@hotmail.com Jociel Ferreira Costa

ORCID: https://orcid.org/0000-0002-3912-9587

Universidade Estadual do Maranhão, Brasil E-mail: jocielfcosta@gmail.com

Jainara Gomes da Silva

ORCID: https://orcid.org/00010-0001-8015-3645 Universidade Federal do Maranhão, Brasil E-mail: jainaragdaniel@hotmail.com

Nyara Cristiane Marques Santos ORCID: https://orcid.org/0000-0002-9218-4796

Universidade Estadual do Maranhão, Brasil E-mail: nyaramarques@hotmail.com

Gabriel Rodrigues Côra

ORCID: https://orcid.org/0000-0002-1774-4853 Universidade Estadual do Maranhão, Brasil E-mail: gabriel.rodrigues.grc07@gmail.com

Rayane Alves Machado

ORCID: https://orcid.org/0000-0002-7883-3374 Universidade Estadual do Maranhão, Brasil E-mail: raya.alves97@gmail.com

\section{Resumo}

Objetivo: Analisar a distribuição de variedades intratipo de Papillomavirus humano em mulheres de grupos minoritários. Metodologia: foram incluídos 5 estudos primários, publicados entre 2016 a 2019, no idioma inglês. Resultados: A prevalência de infecção pelo HPV em mulheres de grupos minoritários foi de $31.72 \%$. Foram pesquisados 54 grupos étnicos em cinco países, Brasil, Índia, Nigéria e Holanda sendo dois estudos realizados no 
Brasil, sendo um no estado do Maranhão e outro no estado Pará. A prevalência entre $21.16 \%$ e 38.89\%. Os genótipos de HPV mais frequentes foram o HPV18, HPV16, HPV31, HPV35, HPV39, HPV45, HPV51, HPV52 e, o HPV58. Apenas um estudo revolução variedades intratipo. Conclusão: A prevalência de HPV de alto risco situou-se entre $2 \%$ e $8 \%$. Os estudos não revelaram análises de linhagens e sublinhagens do HPV 16 e HPV 18. Foram escassas publicações utilizando a métodos de biologia molecular em grupos quilombolas, indígenas e ciganas em países da américa do sul considerando a relevância destes povos na formação cultural nos países latinos.

Palavras-chave: Papillomaviridae; Grupos étnicos; Grupos com ancestrais do continente africano.

\begin{abstract}
Objective: To analyze the distribution of intratype varieties of human Papillomavirus in women from minority groups. Methodology: 5 primary studies, published between 2016 and 2019, in English were included. Results: The prevalence of HPV infection in women from minority groups was 31.72\%. 54 ethnic groups were surveyed in five countries, Brazil, India, Nigeria and the Netherlands, with two studies conducted in Brazil, one in the state of Maranhão and the other in the state of Pará. The prevalence was between $21.16 \%$ and $38.89 \%$. The most frequent HPV genotypes were HPV18, HPV16, HPV31, HPV35, HPV39, HPV45, HPV51, HPV52, and HPV58. Only one research revolution intratype varieties. Conclusion: The prevalence of high-risk HPV ranged between $2 \%$ and $8 \%$. The studies did not reveal lineage and sublineage analyzes of HPV 16 and HPV 18. There were few publications using molecular biology methods in Quilombola, Indigenous and Gypsy groups in South American countries considering the relevance of these peoples in cultural formation in Latin countries.
\end{abstract}

Keywords: Papillomaviridae; Ethnic group; Groups with ancestors from the African continent.

\title{
Resumen
}

Objetivo: Analizar la distribución de variedades intratipo de virus del papiloma humano en mujeres de grupos minoritarios. Metodología: Se incluyeron 5 estudios primarios, publicados entre 2016 y 2019, en inglés. Resultados: La prevalencia de infección por VPH en mujeres de grupos minoritarios fue del 31,72\%. Se encuestaron 54 grupos étnicos en cinco países, Brasil, India, Nigeria y Holanda, con dos estudios realizados en Brasil, uno en el estado de Maranhão y otro en el estado de Pará, con una prevalencia entre 21,16\% y 38,89\%. Los genotipos de HPV más frecuentes fueron HPV18, HPV16, HPV31, HPV35, HPV39, HPV45, HPV51, HPV52 y HPV58. Sólo un estudio revolucionó las variedades intratipo. Conclusión: La prevalencia de VPH de alto riesgo osciló entre el $2 \%$ y el $8 \%$. Los estudios no revelaron análisis de linaje y sublinaje de VPH 16 y VPH 18. Hubo pocas publicaciones que utilizaran métodos de biología molecular en grupos quilombolas, indígenas y gitanos en países de América del Sur considerando la relevancia de estos pueblos en la formación cultural en países latinos.

Palabras clave: Papillomaviridae; Etnias; Grupos con ancestros continentales.

\section{Introdução}

São escassas as publicações científicas que investigam o comportamento do Papilloma virushumano em grupos étnicos complexos a nível mundial e, em especial na américa latina considerando a contribuição destes povos no processo de formação de seu de sua raça e etnia. Assim precisamos investigar o que as publicações científicas revelam quanto a ocorrência de variedades intratipo do HPV nestes grupos minoritários pois a maioria das pesquisas são realizadas em grupos populacionais tradicionais. Vejamos o que os dados epidemiológicos nos demostram a seguir.

O número de casos de câncer atribuíveis ao HPV no mundo em 2012 foi de 630.000, destes 250.000 acometeram mulheres com menos de 50 anos de idade, 220 mil entre 50 a 69 anos de idade e, 50.000 em mulheres maiores de 70 anos de idade. Nos centros menos desenvolvidos do mundo atingiu 410.000 mulheres e nas áreas mais desenvolvidas do mundo acometeu 220.000 mulheres. Nas diferentes regiões do mundo o HPV correspondeu: África (99.000); Norte Africano (12.000); Índia (140.000); Ásia Central e outros (31.000); China (75.000); Japão/Coreia (16.000); Ásia Oriental e outros (59.000); América Latina (78.000); América do Norte (32.000); Europa (87.000); Austrália/Nova Zelândia (1.900); oceânica e outros (1.300) (De Martel, Plummer, Vignat, \& Franceschi, 2017). Percebemos uma lacuna quanto a dados epidemiológicos em grupos e populações em processo social de exclusão. As iniquidades e invisibilidades também encontram expressões nas publicações científicas relacionadas.

No Brasil para o biênio 2018 e 2019 são esperados 16.370 casos novos de câncer de colo de útero, com taxa de risco estimada de $15,4 \%$ por 10 mil mulheres. Neste sentido o câncer cervical ocupa no hanking a terceira posição entre os cânceres femininos com $8,1 \%$ do total de casos. Na região nordeste é o segundo mais incidente com $20,4 \%$ casos por 10 mil mulheres.3 
De maneira geral 70\% dos casos ocorrem mais em áreas com menores índices de desenvolvimento humano (Instituo Nacional do Câncer, 2017; Ferlay et al., 2013).

No estudo de Oliveira (2014) que avaliou fatores associados a não realização do exame Papanicolau em mulheres quilombolas na faixa etária de 18 a 64 anos de idade do município de Vitória da Conquista - BA foi verificado uma prevalência de 27,3\% (95) de mulheres que nunca realizavam o exame de citologia oncótica cervical. Para as mulheres quilombolas que o realizaram há mais de três anos a prevalência foi de $16,4 \%$.

No Brasil são registradas e reconhecidas 2.197 comunidades quilombolas sendo, 2.040 certificados pela Fundação Cultural Palmares onde, 63\% destas localizam-se no nordeste. No maranhão existem registradas 18 cidades com 45 áreas quilombolas. Há 1.229 processos para titulação de terras junto ao INCRA. A estimativa é de são 214 mil famílias e 1,17 milhão de quilombolas em todo o Brasil. 74,73\% das famílias estão em situação de extrema pobreza (Brasil, 2008; Brasil, 2013a). Assim diante de expressivos números de comunidades quilombolas existentes no Brasil o volume de pesquisas realizadas com estão minorias são inexpressivas quando comparadas a população geral.

Há 1.229 processos para titulação de terras junto ao INCRA. A estimativa é de são 214 mil famílias e 1,17 milhão de quilombolas em todo o Brasil. 74,73\% das famílias estão em situação de extrema pobreza. (Brasil, 2008; Brasil, 2013b; Brasil, 2017). A origem dos povos ciganos ainda permanece objeto de investigações, contudo, a teoria mais difundida é a de que este povo se originou na Índia onde, seu processo de dispersão no mundo ocorreu há mais de mil anos. No Brasil os primeiros registros de povos ciganos datam de 1.574. Atualmente pelo menos 3 etnias ciganas vivem no país, cita-se: Calon, Rom e Sinti onde, cada uma delas tem língua, culturas e costumes específicos (Brasil, 2013a; Brasil, 2017).

Tendo em vista a relação do câncer cérvico uterino em grupos que têm maior vulnerabilidade, percebe-se ser exatamente nestes grupos étnicos desfavoráveis a ocorrência de amplas barreiras de acessibilidade aos serviços de saúde, advinda de dificuldades econômicas e geográficas, insuficiência de serviços e questões culturais (Brasil, 2012).

Considerando a comprovação do envolvimento do HPV na gênese das neoplasias epiteliais cervicais através de genótipo de alto risco, evidenciados nas publicações científicas citadas, é razoável admitir a possibilidade de se investigar a ocorrência de variantes e linhagens destes genótipos em grupos étnicos complexos.

A prevalência de HPV 16 e HPV 18 são menores em mulheres negras latinas e mulheres negras não latinas quando relacionadas a mulheres não latinas brancas. Contudo a fusão do material genético do HPV 16 ocorre com mais facilidade entre mulheres negras não latinas e em menor prevalência nas latinas. Este fato corrobora par a observação de anormalidades celulares em citologias neste grupo étnico (Montealegre et al., 2018).

É válido ressaltar que para além de traçar as prevalências dos tipos de HPV, ações educativas são importantes ferramentas para a prevenção e controle da sua circulação do vírus em diferentes grupos etários (Souza et al., 2021). O presente estudo tem como objetivo analisar a distribuição de tipos de Papillomavirus humano em mulheres de grupos minoritários destacando a geografia de ocorrência destes estudos.

\section{Metodologia}

Trata-se de um estudo de revisão integrativa de caráter exploratório descritivo com abordagem quantitativa. Nos estudos com abordagem quantitativa utiliza-se a produção de dados numéricos com medidas de grandezas através de porcentagens, estatísticas, probabilidades, métodos numéricos, métodos analíticos, equações e/ou fórmulas matemáticas. (Pereira, Shitsuka, Moreira; Shitsuka, 2018).

A revisão integrativa tem como objetivo principal condensar obtidos de pesquisas cientificas promovendo detalhar resultados e aprofundando o conhecimento relacionado a questão dos estudos selecionados orientando a tomada de decisão diante de um problema. (Mendes, Silveira, Galvão, 2019). 
O estudo está inserido no Programa de Suporte à Pós-Graduação de Instituições de Ensino Particulares - PROSUP, vinculado Coordenação de Aperfeiçoamento de Pessoal de nível Superior (CAPES). Trata-se de um estudo revisão integrativa de caráter exploratório descritivo. Para elaboração da questão norteadora, utilizou-se a estratégia e/ou acrômio PICo, e por se tratar de um estudo transversal/pesquisa não clínica (frequência) a questão problema norteado foi: considerando para problema/população ("mulheres"), fenômeno de interesse ("Papillomaviridae") e contexto ("Grupos étnicos)". Dessa forma, esta investigação foi conduzida a partir da seguinte questão: Quais as evidências científicas disponíveis sobre a proporção de Papillomavirus humano em mulheres de grupos étnicos minoritários?

O levantamento bibliográfico foi realizado em maio de 2020, por meio da busca nas seguintes bases eletrônicas de dados: Medical Literature Analysis and Retrieval System on-line (MEDLINE) via Pubmed, via Google Scholar e via BVS (Biblioteca virtual em Saúde). Os descritores controlados empregados para a recuperação das produções foram selecionados após consulta dos termos Medical Subject Headings (MeSH) e Decs (Descritores em Ciências da Saúde), e combinados mediante aplicação dos operadores booleanos AND.

A busca totalizou 285 produções, dentre as quais 05 atenderam aos critérios de inclusão e foram selecionadas. Neste percurso após a leitura integral dos títulos e resumos, realizou-se a exclusão de 282 artigos que não se alinhavam ao tema e repetições, textos incompletos e artigos livres indisponíveis. Desse modo, a amostra final foi composta por 05 estudos. O percurso realizado para seleção, triagem, inclusão e exclusão dos estudos será descrito na Figura 1.

Figura 1. Diagrama de fluxo do processo de seleção das produções científicas. Caxias, Brasil, 2020.

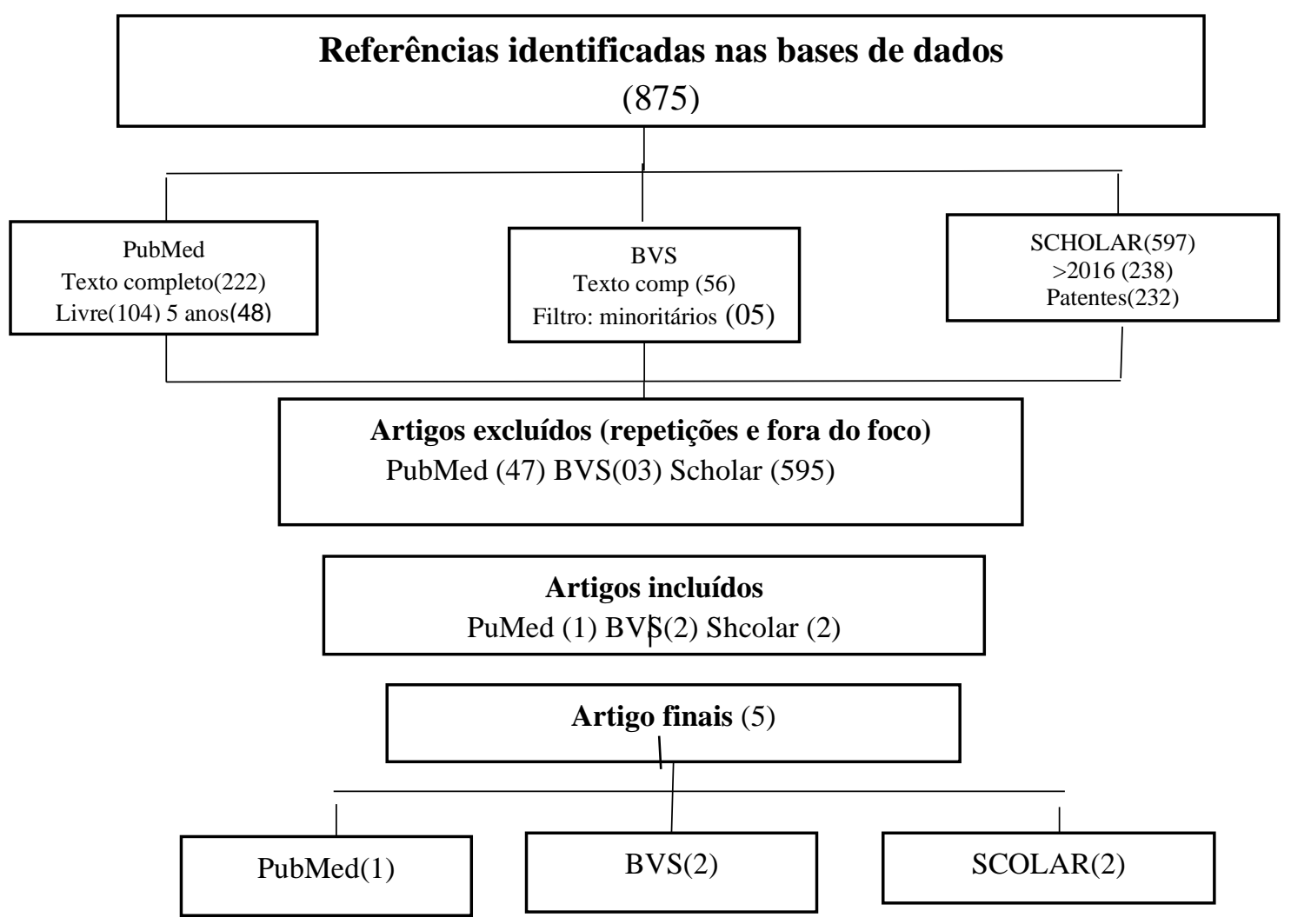

Fonte: Dados da pesquisa.

Foram definidos os seguintes critérios de inclusão: estudos primários (texto completo, publicações nos últimos 5 anos, tetos livres), nos idiomas inglês, português ou espanhol e que abrangessem a temática em estudo. Os critérios de exclusão 
focaram-se nos artigos repetidos e fuga do foco ao tema proposto. Os artigos foram acessados e a inclusão foi realizada de forma independente pelo autor após leitura de títulos e resumos.

A análise dos resultados foi descritiva, em que as produções selecionadas foram organizadas em planilhas no Microsoft Excel, procedendo-se com a construção de quadros de acordo com as variáveis identificadas: prevalência, fatores de riscos, distribuição e variedades intratipo. Ainda, realizou-se o ordenamento do material e a classificação por similaridade semântica, resultando na construção de categorias temáticas.

\section{Resultados e Discussão}

Foram selecionados ao final da busca em três bases 05 estudos transversais que utilizaram swab vaginais e testados quanto ao DNA do HPV e genotipados por meio de PCR. Os estudos utilizaram abordagem quantitativa. Os artigos foram publicados no período 2016 a 2019. Os resultados apresentados segundo a categorias relacionadas ao HPV nas comunidades pesquisadas foram: prevalência, fatores de risco, distribuição de tipos, e distribuição de variedades intratipo.

Dos cinco estudos analisados a prevalência média de infecção pelo HPV em mulheres de grupos minoritários foi de $31.72 \%$. Foram pesquisados 54 grupos étnicos em cinco países, Brasil, Índia, Nigéria e Holanda sendo dois estudos realizados no Brasil, sendo um no estado do Maranhão e outro no estado Pará. Como visualizado no Quadro 1.

Quadro 1. Distribuição dos estudos segundo metodologia e número de pacientes envolvidos. Caxias, Brasil, 2020.

\begin{tabular}{|c|c|c|c|}
\hline Autores e Ano & $\begin{array}{c}\text { Delineamento } \\
\text { e amostra }\end{array}$ & Local coleta & Técnica do estudo \\
\hline Ghosh et al 2019 & $\begin{array}{c}\text { Estudo transversal } \\
\text { N(1.140) }\end{array}$ & Três tribos da Índia & $\begin{array}{c}\text { Questionário, } \\
\text { Citologia, } \\
\text { PCR }\end{array}$ \\
\hline Adebamowo, 2017 & $\begin{array}{c}\text { Estudo de COORT } \\
(11.500)\end{array}$ & $\begin{array}{c}\text { Comunidades na } \\
\text { Nigéria }\end{array}$ & $\begin{array}{c}\text { Questionário Colposcopia } \\
\text { Citologia } \\
\text { PCR }\end{array}$ \\
\hline $\begin{array}{c}\text { De Alberts et al., } \\
2017\end{array}$ & $\begin{array}{c}\text { Estudo transversal } \\
(\mathrm{N}=592)\end{array}$ & $\begin{array}{c}\text { Amsterdã, Suriname, Sul } \\
\text { Asiático, Gana, Marrocos e } \\
\text { Turquia }\end{array}$ & $\begin{array}{c}\text { Questionário } \\
\text { Swab vaginal } \\
\text { PCR }\end{array}$ \\
\hline Nascimento et al., & $\begin{array}{c}\text { Estudo transversal } \\
\text { N(395) }\end{array}$ & $\begin{array}{c}36 \text { Quilombos no maranhão, } \\
\text { Brasil }\end{array}$ & $\begin{array}{c}\text { Questionário, } \\
\text { Citologia, } \\
\text { PCR }\end{array}$ \\
\hline Pinheiro et al 2016 & Estudo transversal & 5 comunidades ribeirinhas \\
& Controle $(76)$ & no Pará-Brasil & Citologia, \\
Casos: $(21)$ & & PCR \\
\hline
\end{tabular}

Fonte: Coleta em bases de dados.

A prevalência na população geral situa-se entre $5 \%$ e $20 \%$ e, entre as mulheres com menos de 34 está prevalência é maior e diminui progressivamente após os 34 anos com curva de nova progressão após os 45 anos. Contudo apenas 10\% dos casos irão persistir relacionada a algum tipo oncogênico de alto risco. Em caso de persistência o risco relativo aumenta de 100 a 300\% sobre as mulheres não infectadas. Geralmente está persistência não é mais identificada após 36 meses. 70\% regridem em até um ano e $90 \%$ após 2 anos. (Fernandes et al., 2013).

No estudo de Ghosh et al. (2019) realizado em 441 mulheres em quatros tribos comunitárias no sul da Índia a prevalência de infecção pelo HPV entre as mulheres tribais foi de 40.6\% (179).

A proporção de casos de câncer em todo o mundo por causas infecciosos nas mulheres no ano de 2012 as faixas etárias são geralmente mais altas cujo pico deu-se entre 40 e 45 anos enquanto nas regiões menos desenvolvidas este pico estava nas mulheres com menos de 40 anos de idade. (De Martel, 2012). 
No estudo estudo multicêntrico realizado em Amsterdã na Holanda no período de 2011 a 2013 por De Alberts (2016) com 592 mulheres provenientes de seis regiões etnias do mundo sendo, 80\% da África Ocidental (Surinamese, Ganense, Turca e Marroquina) e 20\% oriundas do norte da Sul da Ásia onde, das 592 mulheres selecionadas no estudo, 280 (47\%) eram positivas para HPV onde, $53 \%$ apresentavam qualquer tipo de HPV.

No ano de 2018 em todo o mundo considerando do total de 8,6 milhões de casos novos dos 10 cânceres mais comuns entre mulheres, o câncer de cérvice uterina compreendeu 6.6\% e de corpo de útero 4,4\%. Quanto ao total de 4.3 milhões de mortes causadas pelos 10 tipos mais comuns de câncer o câncer de cérvice uterina compreendeu 7.5\%. Analisando a incidência e a mortalidade em regiões do mundo no ano de 2018 verificou-se respectivamente: África Sulista (43.1/20.0); África oriental (40.1/30.0); África ocidental (29.6/23.0); Malásia (27.7/19.0); África central (26.8/21.1); África Sul oriental (17.2/10.0); Europa oriental (16.0/6.1); Caribe (15.5/8.5); América do sul (15.2/7.1); Micronésia/Polinésia (14.2/6.3); América central (13.0/7.0); Ásia sul central (13.0/8.2); Ásia Oriental (10.9/4.1); Norte europeu ( 9.5/2.1); Sul Europeu (7.8/2.2); Norte da África ( 7.2/5.1); Europa Ocidental ( 6.8/2.1); América do Norte (6.4/1.9); Austrália/Nova Zelândia (6.0/1.7); Ásia Ocidental ( 4.1/2.5) (Bray et al., 2018).

No Brasil para o biênio 2018 e 2019 são esperados 16.370 casos novos de câncer de colo de útero, com taxa de risco estimada de 15,4\% por 10 mil mulheres. Neste sentido o câncer cervical ocupa no hanking a terceira posição entre os cânceres femininos com 8,1\% do total de casos. Na região nordeste é o segundo mais incidente com 20,4\% casos por 10 mil mulheres.3 De maneira geral 70\% dos casos ocorrem mais em áreas com menores índices de desenvolvimento humano (Ferlay, 2013).

No estudo transversal de Nascimento et al. (2018) realizado no período de fevereiro 2012 a março de 2013 com 353 mulheres de quilombos do Maranhão da região do Itapecuru e Litoral 328 (92.91\%) mulheres pesquisadas foram negativas para HPV/DNA e 25 (7.09\%) foram positivas. Para as mulheres diagnosticadas com alguma anormalidade citológica, a prevalência de infecção por HPV foi de 24,0\% (11/46).

No estudo observacional realizado no período de 2013 a 2014 por Pinheiro et al. (2016) com 516 mulheres em 04 comunidades ribeirinhas da região do amazonas brasileiro localizadas no nordeste do estado do Pará a prevalência de HPV em casos negativos foi de $81.20 \%$ (419) e de casos positivos foi de $18.79 \%(97)$.

Outro relevante estudo realizado por Adebamovo (2017) em 42 distritos comunitário na Nigéria realizado por com 11.500 mulheres a prevalência de infecção pelo HPV foi de alto risco foi de 54.5\% (598) e HPV de baixo risco foi de $12.6 \%$ (12.6\%). Como visualizado no Quadro 2. 
Quadro 2. Distribuição de tipos de HPV. Caxias, Brasil, 2020.

\begin{tabular}{|c|c|}
\hline AUTOR & TIPOS DE HPV \\
\hline Ghosh et al 2019 & $\begin{array}{r}\text { Prevalência Geral: 441(38.68\%); HPV 18 HPV45; HPV16; Múltiplos } \\
(24.7 \%) ; \text { AR/AR(282); HR/BR(483) }\end{array}$ \\
\hline Adebamowo et al, 2017 & $\begin{array}{c}\text { Positivas 38.89\% (4.473); Negativas 61.11\% (6.727); Alto risco } \\
\text { persistente: 12.52\% (598); Baixo Risco; persistente 2.91\% (139) }\end{array}$ \\
\hline De Alberts et al., 2017 & $\begin{array}{c}\text { Positivas 47.29\% (280); Negativas 52.71\% (312) Qualquer HPV AR: } \\
\text { 29(40\%); 2 Tipos de HPV AR; HPV52; HPV16; HPV51; HPV31:HPV39. }\end{array}$ \\
\hline Nascimentos et al., 2018 & $\begin{array}{c}\text { Positivas 12.6\% (50); Negativas 87.4\%\% (345); HSIL/HPV 6(60\%); } \\
\text { LSIL/HPV 2(28.6\%); HPV16; HPV18; HPV52; HPV58; HPV84; IS39. }\end{array}$ \\
\hline Pinheiro et., 2016 & $\begin{array}{c}\text { Negativas: 76 (78.4\%); Positivas: 21 (21.16\%); HPV6; HPV16; HPV18; } \\
\text { HPV31; HPV:35; HPV52; HPV58; HPV31-18; HPV33-58; HPV16-52. }\end{array}$ \\
\hline
\end{tabular}

Fonte: Coleta em bases de dados.

A prevalência de HPV 16 e HPV 18 são menores em mulheres negras latinas e mulheres negras não latinas quando relacionadas a mulheres não latinas brancas. Contudo a fusão do material genético do HPV 16 ocorre com mais facilidade entre mulheres negras não latinas e em menor prevalência nas latinas. Este fato corrobora par a observação de anormalidades celulares em citologias neste grupo étnico. (Montealegre et al., 2018).

\subsection{Fatores de risco}

$\mathrm{Na}$ análise de fatores de risco de mulheres positivas tribais no sul da Índia $53.5 \%$ (235) tinham idade entre 31 e 45 anos; 57,4\% tinham baixa escolaridade; $57.1 \%$ (252) eram dona de casa; $56 \%$ (247) tinham baixo nível socioeconômico; 21.3\% (94) fumavam; 86.4\% (381) eram multíparas (Gosh et al., 2019). 
Quadro 3. Distribuição fatores de risco na população étnico HPV positivas. Caxias, Brasil, 2020.

\begin{tabular}{|c|c|c|c|}
\hline Variáveis & Estudos & $\mathbf{N}$ & $\%$ \\
\hline$<30$ anos & 2 & $\begin{array}{l}- \\
19\end{array}$ & $\begin{array}{l}77.3 \% \\
17.3 \%\end{array}$ \\
\hline 31 a 50 anos & 2 & $\begin{array}{c}18 \\
366\end{array}$ & $\begin{array}{r}20.3 \% \\
83 \%\end{array}$ \\
\hline Casada & 2 & $\begin{array}{l}25 \\
25\end{array}$ & $\begin{array}{l}89.7 \% \\
10.4 \%\end{array}$ \\
\hline Baixa escolaridade & 3 & $\begin{array}{c}- \\
39 \\
253\end{array}$ & $\begin{array}{l}57.4 \% \\
26.5 \% \\
57.4 \%\end{array}$ \\
\hline Fumante & 2 & $\begin{array}{l}280 \\
94\end{array}$ & $\begin{array}{l}24.6 \% \\
21.3 \%\end{array}$ \\
\hline Alcoolismo & 1 & 18 & $12.4 \%$ \\
\hline Menarca $<12$ anos & 1 & 21 & $3 \%$ \\
\hline Menopausada & 1 & 140 & $31.7 \%$ \\
\hline Multípara & 3 & $\begin{array}{c}- \\
44 \\
381\end{array}$ & $\begin{array}{l}85.7 \% \\
13.5 \% \\
86.4 \%\end{array}$ \\
\hline Atividade sexual antes 15 anos & 1 & 26 & $17.1 \%$ \\
\hline Mais de 1 parceiro & 1 & 29 & $13.5 \%$ \\
\hline Uso de contraceptivos orais & 1 & 17 & 24.3 \\
\hline Sinais de IST & 1 & 06 & $5.2 \%$ \\
\hline
\end{tabular}

Fonte: Coleta em bases de dados.

Em um estudo realizado por Adebamowo (2017) com 11.500 mulheres no período de 2014 a 2016, muitas das mulheres inscritas estavam na terceira ou quarta década de vida. As maiorias das participantes caracterizavam-se como: casadas 77\% (8832/11.500), monogâmicas e vivia com seus cônjuges 86\% (7.556/8.832). 55\% das participantes tinham baixa escolaridade e eram empregadas $36 \%$ (4.175/11.500). Cerca de $16 \%$ dos participantes do estudo fizeram sexo oral e $<1 \%$ fez sexo anal. Entre as mulheres positivas para o HPV, 4773 (100\%) tinham práticas sexual com penetração vaginal, 816(17.1\%) praticavam sexo oral e $27(0.6 \%)$ sexo anal. 
A transmissão do HPV ocorre essencialmente por via sexual (oral-genital, genital-genital e genital-manual) em ambos os sexos e, a partir da infecção os susceptíveis podem se tornar portadores subclínicos e transmissores. A cópula anal e vaginal não é condição essencial para a penetração do vírus havendo transmissão por via direta por meio do contato com pele e mucosa por contato íntimo com a genitália ou outras mucosas infectadas. (Fernandes et al., 2013; Tristão et al., 2012; Cubie, 2013).

No estudo de De Alberts (2016) a mediana de idade da infectadas pelo HPV foi 27 anos; 92\% das mulheres pesquisada faziam uso de contraceptivos orais; $94 \%$ faziam uso de álcool no ano anterior; $8 \%$ apresentavam sinais de infecção sexualmente transmissível. A maioria tinha vida sexualmente ativa com início de atividade sexual ainda jovem, fazendo sexo apenas com um parceiro estável.

De maneira geral as mulheres quilombolas entrevistadas no estudo de Nascimento et al (2018) se caracterizavam como de baixo nível socioeconômico, casadas $60 \%$ (212); tinham entre 30 e 50 anos de idade 45\% (160). A faixa etária das mulheres pesquisada variou entre 13 e 82 anos de idade com média de 36 anos; iniciaram sua atividade sexual < 15 anos $16 \%$ (22); tinham um único parceiro sexual 42.7\% (151); teve menarca antes dos 12 anos de idade $14.6 \%$ (21); teve mais de uma gestação 14.\% (14); e utilizavam contraceptivos 9.5\% (06). As mulheres HPV positivas mostraram 6,5 vezes mais chances de serem diagnosticadas com anormalidades citológicas. Os demais fatores de risco analisadas não mostraram associação significante com a detecção de anormalidades citológicas.

A ocorrência de fatores de risco coassociados ao HPV é probabilística na gênese da doença, exercendo fortes influências, os fatores ambientais e hereditários sendo, o fator ambiental responsáveis por 80 a $90 \%$ dos casos. O envelhecimento da mulher aumenta sua susceptibilidade. (Lee, Hashibe, 2014). Vários estudos correlacionam o HPV 16, a linhagem não europeia e, o referem como mais cancerígenos tendo risco duplo para oncogenicidade. (HPV16EUR-350T versus 350G) (Nishimura et al., 2015).

\subsection{Distribuição de tipos}

Na distribuição de coinfecção de HPV-alto risco com /HPV- baixo foi observado a ocorrência de 483 casos em mulheres tribais com destaque para as maiores distribuições de coinfecção: HPV45/HPV87( $\left.1^{\circ}\right)$; HPV45/HPV97( $\left(2^{\circ}\right)$; HPV18/HPV97(3º); HPV18/HPV87(4º). Na distribuição de HPV-baixo risco com /HPV-baixo risco foi observado a ocorrência em 201 mulheres tribais sendo, HPV87/HPV97 $\left(1^{\circ}\right)$. No geral nas mulheres tribais foi observada uma maior tendência de coinfecção para HPV-alto risco com HPV-baixo risco. Os subtipos prevalentes de HR-HPV entre mulheres tribais no sul da Índia foram: HPV-18 (28,3\%), HPV-45 (22,8\%) e HPV-16 (10,7\%). As infecções por subtipos únicos de HPV foram observados em $14,4 \%$ e subtipos múltiplos de HPV em $24.7 \%$ da população tribal. As coinfecções virais com os subtipos de HR-HPV foram predominantes nestas, com 59,7\% de casos. Na análise de coinfecção de HPV-alto risco e HPB-alto risco foi verificado a ocorrência em 282 mulheres tribais o hanking proporcional: HPV18/HPV45 (1 $\left.{ }^{\circ}\right)$; HPV16/HPV45(2 $2^{\circ}$ ) (Ghosh et al.,2019).

De acordo com Crow (2012) na fase de infecção ativa (NICI), 18,5\% são ocasionados pelo HPV 16 e 5.8\% pelo HPV 18. Na fase de lesão precursora NIC (NIC II e III) 44,1\% e 7\% são identificados o HPV16 e o HPV18 respectivamente. Contudo na lesão invasiva 54,4\% são ocasionadas pelo HPV16 e 16,5\% são provocados pelo HPV18. Os dois genótipos sozinho são responsáveis por de 70,9\% dos casos de cânceres.

As distribuições dos genótipos de vírus HPV em grupos quilombola no Maranhão foram: 68 (24,2\% - 11/46); 58 (19,8\% - 9/46); 52 e 31 (10,8\% - 5/46 cada) e 62 (8,8\% - 4/46) foram os mais prevalentes. Em relação à presença de HPV nos diferentes resultados citológicos segundo os tipos de alto risco oncogênico foram mais frequentes $(78,3 \%$ 36/46) que os de baixo risco oncogênico (21,7\%-10/46). A prevalência foi maior nos casos de HSIL (75,0\%), seguida por ASC-H (50\%), LSIL 
(33,4\%) e ASC-US (14,3\%). Dentre os casos de coinfecção de dois tipos de alto risco destacaram: HPV31/18 2 (2.1\%); HPV33/58 1 (1\%); HPV16/52 1(1\%) (Nascimento et al., 2018).

Em grupos étnicos pesquisados na Holanda foi observada nas mulheres a seguinte distribuição: qualquer tipo de HPV (53\%), HPV de alto risco (42\%). O HPV tipo 16 e HPV tipo 18 foram detectados em todos os grupos, mas foram mais comuns entre mulheres de comunidades turcas (HPV-16; 13\%) e holandesas (HPV-18; 10\%). O HPV16 e o HPV 18 foram detectados em todos os grupos étnicos comunitários pesquisados (Alberts, 2016). Após o seguimento das mulheres em comunidades na Nigéria, 598 casos (54\%) desenvolveram persistência para o HPV de alto risco e, 139 (12.6\%) desenvolveram persistência para o HPV de baixo risco (Adebamovo, 2017).

A integração do DNA do HPV 16 aos genes do hospedeiro ocorre mais provavelmente entre mulheres negras não hispânicas contribuindo assim para as altas taxas de citologia com anormalidades e displasias cervicais (Montealegre, 2017).

O HPV 18 é o segundo tipo viral mais ligado ao carcinoma do colo do útero. Contudo, a totalidade de caso é muito menor que o HPV 16. Pesquisas ressaltam que a diversidade no potencial carcinogênico das variantes do HPV 18 está associada a uma distribuição geográfica, racial e demonstra correspondência de distribuição com o HPV 16 (Arroyo et al., 2012; Sun et al., 2012).

\subsection{Distribuição de variantes intratipo}

O único estudo que revelou a arvore filogenética de variantes do HPV16 com base no L1 foi produzido por Gosh et al. (2019) em amostras da população tribal demonstrados em 10 grupos (I a X) com 1,8\%, 7,9\%, 4,4\%, 27,4\%, 7,1\%, 9,7\%, Amostras de 6,2\%,4,4\% e 15,9\%, respectivamente. Entre essas 7,1\%, as amostras alinhadas Sub-linhagem norte-americanaD1 e 0,8\% alinhada à sub-linhagem-africana-2-B2 (Ghosh et al., 2019).

As sublinhagens do HPV 16 estão relacionadas a risco de desenvolver as lesões em grau diferentes variando em A4 (adenocarcinoma); B (maior risco para NIC III); C (NIC III e Câncer); D2 (Câncer, Lesões Glandulares e adenocarcinoma) D3 (NIC III e Câncer) Variantes do HPV 16 quando infeccionam mulheres estas apresentam risco aumentado ao se tratar da correspondência a etnia desta mulher. (Mirabelo, 2016). Outras consequências são correlacionadas as linhagens e sublinhagens mais comuns do HPV 16: A, A4 (sublinhagem asiática). As sublinhagens que tem relações com lesões precursoras e cânceres, cita-se A1(CIN I); A3(CIN II) e A4 (NIC III e carcinoma invasor) (Liv, Pan, Gao, Ke, \& Lu, 2017).

\section{Conclusão}

O estudo permitiu uma análise comparativa do comportamento da infecção pelo HPV em grupos étnicos minoritários muitas vezes invisíveis as pesquisas e políticas de redução das iniquidades.

Dos cinco estudos analisados a prevalência média de infecção pelo HPV em mulheres de grupos minoritários foi de $31.72 \%$. Foram pesquisados 54 grupos étnicos em cinco países, Brasil, Índia, Nigéria e Holanda sendo dois estudos realizados no Brasil, um no Maranhão e outro no Pará. Todos os estudos foram transversais e utilizaram métodos avançados de PCR. A prevalência de genótipos de alto rico ficou entre $2 \%$ e $8 \%$ com destaque para o HPV 16, HPV18, HPV35, HPV45, HPV52 e HPV58\%. Na grande maioria dos estudos foi revelada a tendência de infecção e persistência de genótipos de alto risco bem como coinfecção com outros tipos de alto e baixo risco.

A pesquisa revelou a circulação do HPV com a presença de tipo de alto risco nesteas populações demonstrando a necessidade de estender pesquisas de rastreamentos nestes grupos minoritários utilizando técnicas de genotipagem, sequenciamento e hibridização para determinar a prevalência e variedades de HPV's. Faz-se também necessário o desenvolvimento de ações de prevenção e controle e atividade de educação em saúde para minimizar efeitos do HPV nestas comunidades minimizando com isso efeitos de iniquidades e desigualdades presente ao longo da história. 


\section{Referências}

Adebamowo S. N, Dareng, E. O, Famooto, A. O., Offiong, O. O., Obend, K., Adebayo, A. et al. (2017) Cohort Profile: African Collaborative Center for Microbiome and Genomics Research's (ACCME's) Human Papillomavirus (HPV) and Cervical Cancer Study. International Journal of Epidemiology, 46(6):1745-45. https://academic.oup.com/ije/article/46/6/1745/3611017

Alberts, C. J., Vos, R. A., Borgdorff, H., Vermeulen, W., Bergen, J., Bruisten, S. M. et al. (2016) Vaginal high-risk human papillomavirus infection in a crosssectional study among women of six different ethnicities in Amsterdam, the Netherlands: the HELIUS study. Sexually Transmitted Infectionsk, 92:611-18. $10.1136 /$ sextrans-2015-052397

Arroyo, S. L., Basaras, M., Arrese, E. H., Andía, S. D., Esteban, V., \& Garcia-Etxebarria, K. J. (2012). Human Papillomavirus (HPV) genotype 18 variants in patients with clinical manifestations of HPV related infections in Bilbao, Spain. Virology Journal, 9(1):258. http://virologyj.biomedcentral.com/articles/10.1186/1743-422X-9-258

Brasil (2017). Ministério da Saúde. Política nacional de saúde Integral da população negra. Brasília: Secretaria de gestão estratégica e participativa. http//C:/Users/wa200/AppData/Local/Microsoft/Windows/INetCache/IE/5 DZSC69E/politica_nacional_saude_populacao_negra.pdf.

Brasil (2013a). Guia de políticas Públicas para as Comunidades Quilombolas. Secretaria de Políticas de Promoção da Igualdade Racial Secretaria De Políticas Para Comunidades Tradicionais. Disponível em http//C:/Users/wa200/AppData/Local/Microsoft/Windows/INetCache/ie/qg5674rn/ guia-pbq.pdf.

Brasil (2013b). Secretaria de políticas de promoção da igualdade racial. Relatório Executivo da I Semana Nacional dos povos ciganos. http://www.seppir.gov.br/ portal-antigo/arquivos-pdf/relatorio-executivo-brasil-cigano1.

Brasil (2012). Ministério da Saúde. Estimativa 2012 - Incidência do câncer no Brasil. Instituto Nacional do Câncer José Alencar Gomes da Silva. https://pt.scribd.com/document/101038207/Estimativa-2012-Incidencia-de-Cancer-no-Brasil.

Brasil (2008). Ministério da Saúde (Brasil). Atualiza o quantitativo populacional de residentes em assentamentos da reforma agrária e de remanescentes de quilombos, por município, para cálculo do teto de Equipes Saúde da Família, modalidade I, e de Equipes de Saúde Bucal da estratégia Saúde da Família. Portaria n ${ }^{\circ} 90$ de janeiro de 2008. Brasília: Ministério da Saúde. http://189.28.128.100/dab/docs/legis lacao/portaria90170108.pdf.

Brasil (2018). Instituto Nacional do Câncer. Coordenacao de Prevencao e Vigilancia. Estimativa 2018: incidência de câncer no BrasillNCA, 2017. http://www.inca.gov.br/estimativa/2018/estimativa-2018.pdf.

Bray, F., Ferlay, J. M. E, Soerjomataram, I., Siegel, R. L., Torre, L. A., \& Jemal, A. D. V. M (2018). Global Cancer Statistics 2018: GLOBOCAN Estimates of Incidence and Mortality Worldwide for 36 Cancers in 185 Countries. CA Cancer J Clin, 68:394-424. https://acsjournals.onlinelibrary.wiley.com/doi/pdf/10.3322/caac.21492

Crow, J. M (2012). HPV: The Global Burden Human papillomavirus (HPV) has become synonymous with cervical cancer, but its actual footprint is much bigger. $n$ a t u r e, 488(30). https://www.nature.com/articles/488S2a.pdf

Cubie, H. A (2013). Diseases associated with human papillomavirus infection. Jour Virology, 445(12):21-34 https://reader.elsevier.com/reader/sd/pii/s0042682213003565?token=9cdfd18b950bc311316ab511abdecb97922ccf53b4508693e7dc70af3d2c12028a6ac0cadcf $6328 \mathrm{bd} 92 \mathrm{~b} 11 \mathrm{e} 9 \mathrm{a} 2 \mathrm{e} 9 \mathrm{def} 6$

De Martel, C., Plummer, M., Vignat, J, \& Franceschi, S (2017). Worldwide burden of cancer attributable to HPV by site, country and HPV type. Int. J. Cancer, 141:664-70. https://www.ncbi.nlm.nih.gov/pmc/articles/PMC5520228/pdf/IJC-141-664.pdf

Fernandes, J. V, De Araujo, J. M. G., \& Fernandes, T. A. A. M. F (2013). Biology and natural history of human papillomavirus infection. Open Access Journal of Clinical Trials, 5:1-12. https://sci-hub.tw/10.2147/oajct.s37741

Ferlay J, Soeriomataram I, Dikshit R, Eser S, Mathers C, \& Rebelo M (2013). Cancer incidence and mortality worlwide. Lyon, IARC. http//C:/Users/Ross/Downloads/Ferlayetal-2015-International_Journal_of_Cancer.pdf

Ghosh, S. S, Ranjitha S., Pattanshetty, S. M. P., Mallya, S. D., Pandey, D., Kabekkodu S.P., Kamath, V.G., Prabhu, N., D’souza, J., \& Satyamoorthy K (2019). Human papilloma and other DNA virus infections of the cervix: A population based comparative study among tribal and general population in India. PLOS ONE. https://doi.org/10.1371/journal.pone.0219173

Mendes, K. S., Silveira, R. C. C. P., \& Galvão, C. M (2019). Use of the bibliographic reference manager in the selection of primary studies in integrative reviews. Texto \& contexto enferm, 28: e20170204. Available from: https://periodicos.ufpel.edu.br/ojs2/index.php/enfermagem/article/view/19924/11996

Mirabelo, L., Yeager, M., Cullen, M., Boland, J. F, Chen, Z., Wentzensen N., Zhang, X., Yu, K., Yang, Q., Mitchell, J., Roberson, D., Bass, S., \& Xião, Y (2016). HPV16 Sublineage Associations With Histology-Specific Cancer Risk Using HPV Whole-Genome Sequences in 3200 Women. JNCI J Natl Cancer Inst,108(9):djw100. https://www.ncbi.nlm.nih.gov/pmc/articles/PMC5939630/.

Montealegre, J. R., Gregory, E. C., Peckham, D. D., Marquez, D. L., Guillaud, M. K., Storthz, A., Follen, M. \& Follen, S. M. E (2018). Racial/ethnic differences in HPV 16/18 genotypes and integration status among women with a history of cytological abnormalities. Gynecologic Oncology. https://scihub.tw/10.1016/j.ygyno.2017.12.014

Nascimento, M. D. S. B. N., Vidal, F. C. B., Da Silva, M. A. C. N., Batista, J. E., Barbosa, M. C. L., Muniz Filho, W. E., Bezerra, G. F. B., Viana, G. M. C., Branco, R. C. C., \& Brito, L. M. O (2018). Prevalence of human papillomavirus infection among women from quilombo communities in northeastern Brazil. BMC Women's Health, 18:1. 10.1186/s12905-017-0499-3.

Nishimura, M., Miyatake, T., Nakashima, A., Miyoshi, A., Mimura M., Masaaki, N., Ogita, K., \& Yokoi, T (2015). Clinical Significance of Atypical Squamous Cells of Undetermined Significance among Patients Undergoing Cervical Conization. Asian Pacific Journal of Cancer Prevention, http://journal.waocp.org/article_31712_1c3881d5b136692cf86ec067b4ab427b.pdf 
Research, Society and Development, v. 10, n. 10, e152101018518, 2021

(CC BY 4.0) | ISSN 2525-3409 | DOI: http://dx.doi.org/10.33448/rsd-v10i10.18518

Oliveira, M. V (2014). Prevenção do câncer de colo uterino em mulheres quilombolas do município de vitória da conquista, Bahia, Brasil. Dissertação de Mestrado. Belo Horizonte. http://www.bibliotecadigital.ufmg.br/dspace/handle/1843/ buos-9p8kqu.

Pereira, A. S. P., Moreira S. D., Pereira, D. J., \& Shitsuka, R (2018). Metodologia da pesquisa científica. UFSM.

Pinheiro, M. C. N., Brito, E. B., Pinheiro, D. N. P., Borges, B. E. S., Soares, E. S., Gomes, J. A. N., \& Fuzii, H. T. Principais genótipos de papilomavírus humano em mulheres ribeirinhas na amazônia brasileira. Rev Bras Promoç Saúde, 29(1): 68-74. https://www.redalyc.org/pdf/408/40846964010.pdf

Plummer, M., De Martel, C., Vignat, J., Jacques, B., \& Freddie, F. S (2016). Global burden of cancers attributable to infections in 2012: a synthetic analysis. Lancet Glob Health, 4:e609-16. https://www.thelancet.com/action/showPdf?pii=S2214-109X\%2816\%2930143-7

Regina, E. D (2014). Guia prático de Medicina Baseada em Evidências. Cultura Acadêmica.

Souza, J. O., Pires, T. M. V., Soares, I. L., \& Pereira, A. C. O (2021). Panorama geral do enfrentamento ao Papilomavírus Humano (HPV) no Brasil e no Mundo: Uma revisão de literatura com foco em estratégias educativas. Res, Soc Develop, 10(6):e56410615848. 10.33448/rsd-v10i6.15848.

Sun, Z. L., Zhitao, L., Jianhua, W., Guili, Z., Weiqiang, Y., Lianxia, L., \& Chao, R. Q (2012). Genomic Polymorphism of Human Papillomavirus Type 52 in Women from Northeast China. International Journal of Molecular Sciences, 13(12):14962-72.

Tristão, W., Ribeiro, R. M. P., \& De Oliveira, C. A (2012). Epidemiological study of HPV in oral mucosa through PCR. Brazilian Journal of otorhinolaryngology 78(4). https://reader.elsevier.com/reader/sd/pii/S1808869415308892?token=a578a01005a63451cd78ba6d7eb6d168fa4edb411b9b8 724c64c90f27cf3f61ef09e28c80094976b195a48bde11a1a7a

Ying, L., Yaqi, P., Weijiao, G., Yang, K., \& Zheming, Lu (2017). Whole-Genome Analysis of Human Papillomavirus Types 16, 18, and 58 Isolated from Cervical Precancer and Cancer Samples in Chinese Women. Scientific RepoRts. 7: 263. 10.1038/s41598-017-00364-9 